\title{
Antifungal Activity of Peruvian Banana Peel (Musa paradisiaca L.) on Candida albicans: An In Vitro Study
}

\author{
Monica Loyaga-Castillo ${ }^{1}$, Roger D Calla-Poma ${ }^{2}$, Rubén Calla-Poma ${ }^{3}$, Margarita F Requena-Mendizabal ${ }^{4}$,
} Pablo A Millones-Gómez ${ }^{5}$

\begin{abstract}
Aim: The purpose of this study was to compare the antifungal activity of three concentrations of a hydroethanolic extract of the Musa $\times$ paradisiaca peel against Candida albicans strain ATCC 10231.

Materials and methods: The agar diffusion method was used, and the culture medium used was Sabouraud agar. Petri dishes were prepared with concentrations of 10,30 , and $50 \%$ of hydroethanolic extract of the $M$. $\times$ paradisiaca peel; nystatin was used as a positive control, and $96 \%$ ethanol was used as a negative control. After 24 hours of incubation, each plate was examined, and the diameters ( $\mathrm{mm}$ ) of the growth inhibition halos were measured around each well using a digital vernier caliper.

Results: The results showed that the antifungal activity of the extract varied, depending on the concentration, as shown using analysis of variance (ANOVA; $p<0.05$ ). When comparing the different concentrations, it was found by Duncan test that the greatest activity was obtained at $50 \%$. Conclusion: It was concluded that the hydroethanolic extract of $M$. $\times$ paradisiaca at $50 \%$ exerted a greater antifungal effect on the strain of $C$. albicans than did the extract at lower concentrations.

Clinical significance: By knowing the antimicrobial effect of $M$. $\times$ paradisiaca, this substance can be effectively used in products aimed to cure candidiasis infection.

Keywords: Antifungal, Banana, Candida albicans, Hydroethanolic extract, Musa $\times$ paradisiaca, Oral candidiasis.

The Journal of Contemporary Dental Practice (2020): 10.5005/jp-journals-10024-2827
\end{abstract}

\section{INTRODUCTION}

Oral candidiasis is a major health problem worldwide. This fungal pathogen is very important for humans, because of its clinical significance and for scientific research. ${ }^{1}$

Candidiasis in the oral cavity is an infection caused by fungi, and the most frequently isolated pathogen is Candida. This fungus is usually a saprophytic colonizing agent of the gastrointestinal and genitourinary systems, but it is also found in infections involved in the modification of the oral microflora, as well as in systemic diseases, and has been shown to weaken the normal functioning of the immune system. The most frequently implicated and most damaging species of this genus is Candida albicans. ${ }^{2}$

Today, the treatment of candidiasis is based on antimicrobials in different pharmaceutical forms. However, an optimal therapeutic result is not always obtained. ${ }^{3-5}$ At the same time, the use of phytodrugs can be considered a useful alternative offered by traditional and natural medicine. ${ }^{6,7}$

The banana peel accounts for approximately $30 \%$ of the weight of the fruit. Potential applications for banana peel depend on its chemical composition. The banana peel is rich in dietary fiber, proteins, essential amino acids, polyunsaturated fatty acids, and potassium; between efforts to use the shell protein, methanol, ethanol, pectins, and enzymes coal has been obtained vegetable, an alternative fuel source for cooking. Also we consider it can be a potential source of antioxidants and antimicrobials, as well as phytochemical compounds with activity against free radicals. ${ }^{8,9}$ Synthetic drugs available cause adverse effects and lead to fungal resistance; their application is also associated with higher costs. Thus, natural product alternatives, such as Musa $\times$ paradisiaca, which contains flavonoids, associated with antifungal activity, are a therapeutic option for the treatment of this problem.
1Department of Dentistry, Universidad Católica Los Ángeles de Chimbote, Perú

${ }^{2-4}$ Department of Oral Rehabilitation, Universidad Nacional Mayor de San Marcos, Perú

${ }^{5}$ Posgraduate School, Universidad Norbert Wiener, Lima, Perú

Corresponding Author: Pablo A Millones-Gómez, Posgraduate School, Universidad Norbert Wiener, Lima, Perú, Phone: +51 944908425 , e-mail: pablodent@hotmail.com

How to cite this article: Loyaga-Castillo M, Calla-Poma RD, Calla-Poma R, et al. Antifungal Activity of Peruvian Banana Peel (Musa paradisiaca L.) on Candida albicans: An In Vitro Study. J Contemp Dent Pract 2020;21(5):509-514.

Source of support: Nil

Conflict of interest: None

Given all of the above, the purpose of this study was to compare the antifungal activity of three concentrations of a hydroethanolic extract of the $M$. $\times$ paradisiaca peel against $C$. albicans strain ATCC 10231.

\section{Materials and Methods}

\section{Collection and Taxonomic Identification of the Plant Sample}

In May $20171 \mathrm{~kg}$ of stems and leaves of M. × paradisiaca was collected, which included the flower of the plant species and taken to the Herbarium Truxillense of the National University of Trujillo, Peru, for the identification and taxonomic determination.

A total of 50 bananas were collected from the district of Piura, Province of Sullana, Region of Piura, Peru, and placed in a cardboard 
box with holes. The box was taken to the School of Pharmacy and Biochemistry of the National University of Trujillo for further processing

\section{Preparation of the Plant Sample Selection and Washing}

Bananas in good condition were selected, i.e., not showing attacks by fungi and insects or discoloration. The fruits were washed with distilled water, followed by disinfection with $0.5 \%$ sodium hypochlorite. Subsequently, the bananas were dried for 48 hours. The peel was cut into pieces of approximately $1 \mathrm{~cm} \times 1 \mathrm{~cm}$ and then placed in Kraft paper and dried in an oven at $40^{\circ} \mathrm{C}$ (Figs 1A to C).

\section{Homogenization and Sieving}

The peels were pulverized with a mortar and pestle into a powder and then passed through a set of sieves to obtain particles of homogeneous size (Figs 1D to F).

\section{Storage}

The obtained powder was stored in a wide-mouth amber glass jar.

\section{Preparation of the Hydroethanolic Extract}

\section{Alcoholic Maceration}

A total of $100 \mathrm{~g}$ of the banana peel powder was placed in a widemouth amber glass jar. Then $70 \%$ ethanol was added to cover the sample by more than $2 \mathrm{~cm}$ and mixed well, considering that the mixture should occupy a maximum of three fourths of the container. The container was covered, and the sample was macerated for 7 days, with shaking for 15 minutes twice a day.

\section{Preparation of a Dry Extract}

Afterward the macerate was filtered through Whatman No. 1 filter paper using a vacuum pump. The filtrate was called a hydroethanolic extract. Subsequently, the hydroethanolic extract was concentrated in a rotavapor until a syrupy mass was obtained, which was dried in an oven at $40^{\circ} \mathrm{C}$. The resulting product was called a dry extract.

\section{Preparation of Concentrations}

These extracts were prepared at concentrations of $10 \%, 30 \%$, and $50 \%$ in 70 Gay Lussac (GL) ethanol. The hydroethanolic extracts of each plant sample were stored in amber glass bottles at $4-8^{\circ} \mathrm{C}$ until use.

\section{Microbial Species}

The strain of C. albicans ATCC 10231 was obtained from the GenLab Laboratory of Peru SAC-Lima and preserved in the Microbiology Laboratory of the Faculty of Medicine of the National University of Trujillo. Once the strain was obtained, it was reactivated in test tubes with screw cap using Sabouraud dextrose agar medium 4\% at $25^{\circ} \mathrm{C}$ for 48 hours for C. albicans ATCC 10231 (Fig. 2A).

\section{Inoculum Preparation}

For the preparation of a suspension, C. albicans was grown for 48 hours and then the cells were suspended in a sterile $0.85 \%$ saline solution. The turbidity was adjusted to the equivalent of 0.5 McFarland standard for C. albicans. Inocula were prepared by taking one colony of the reactivated strain of C. albicans with a Kohler loop under sterile conditions and then suspending the biomass in $5 \mathrm{~mL}$ of $0.9 \%$ physiological saline in a test tube until reaching an equivalent concentration of 0.5 on the McFarland scale by measuring the optical density using a nephelometer.

\section{Sample Inoculation}

Sabouraud agar was used as the culture medium for the agar diffusion test. To each plate, $50 \mu \mathrm{L}$ of the standardized sample was added with a micropipette and spread with a sterile swab over the surface of the culture medium, allowing 3-5 minutes for drying. Ten petri dishes were prepared with the strain of $C$. albicans. Each plate was labeled with a permanent marker and corresponded
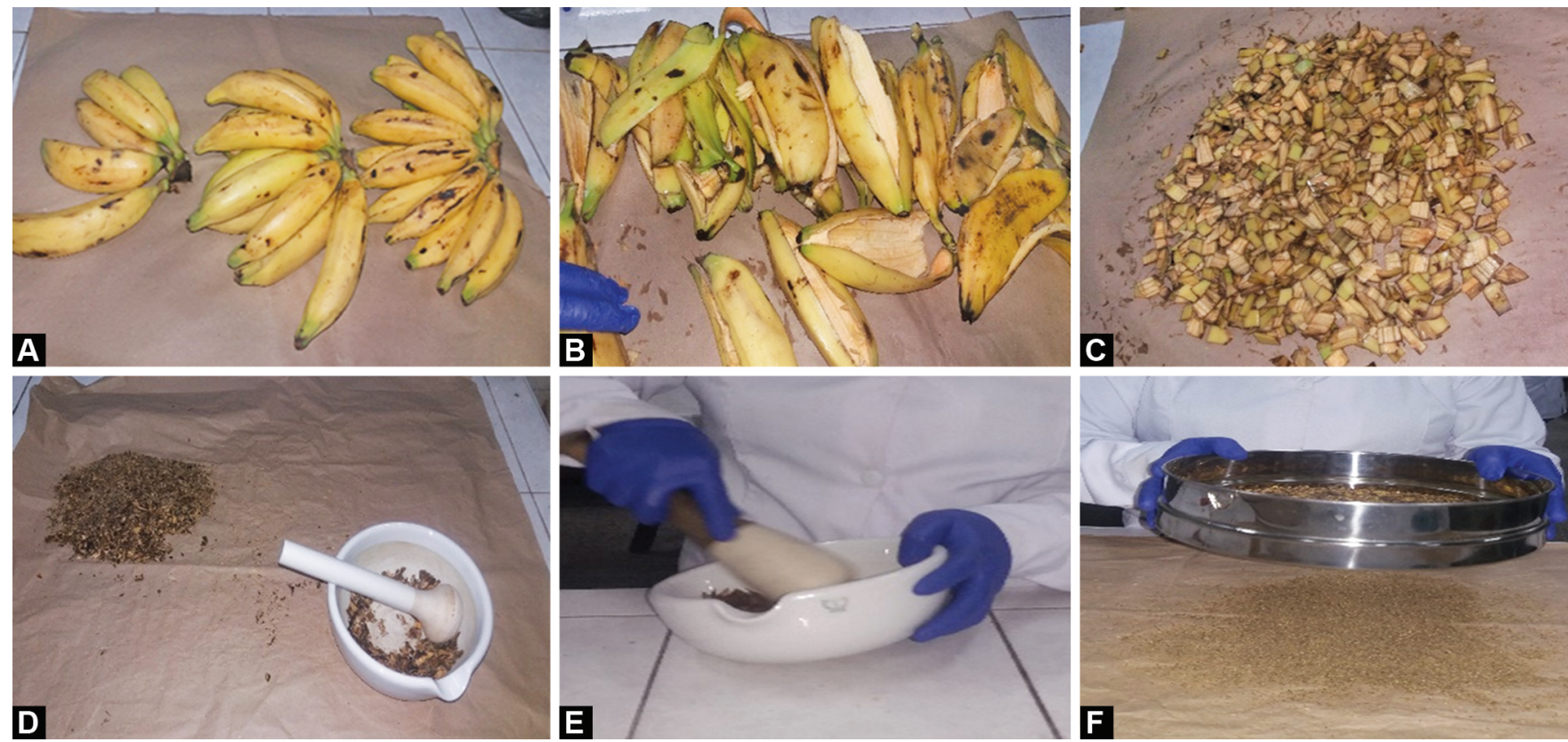

Figs 1 A to F: Preparation of the plant sample: (A) Bananas were selected in good condition; (B) The fruit and peel were dried; (C) The peel was cut into pieces of approximately $1 \mathrm{~cm} \times 1 \mathrm{~cm}$; (D-F) Homogenization and sieving: The peels were pulverized with a mortar and pestle into a powder and then passed through a set of sieves to obtain particles of a homogeneous size 

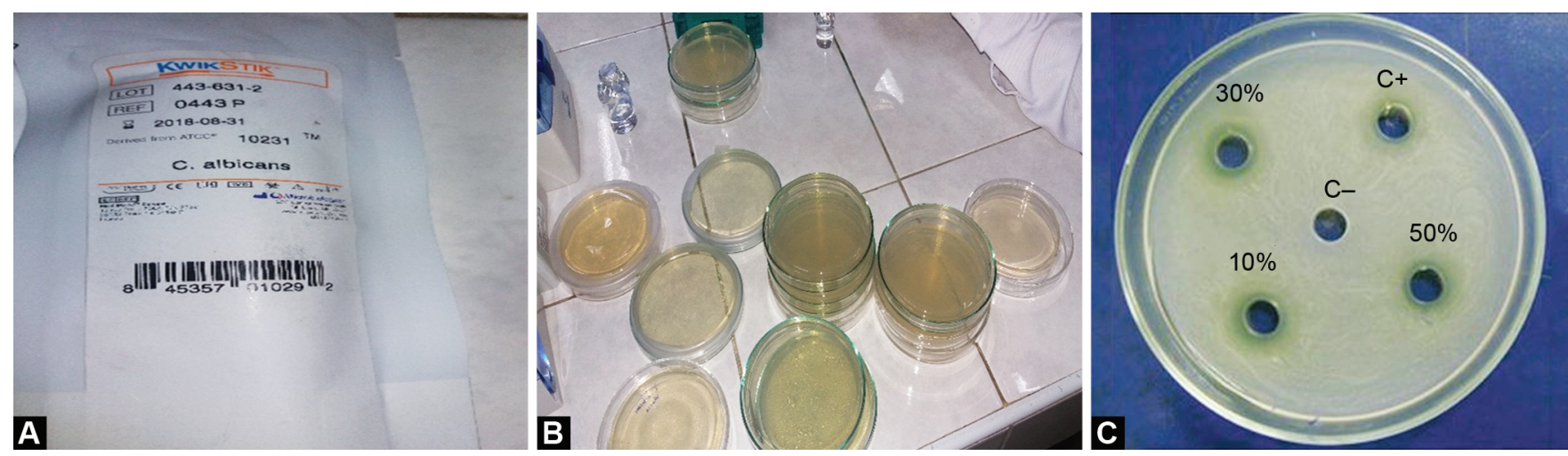

Figs 2 A and B: Antimicrobial test: (A) Strain of Candida albicans ATCC 10231; (B) Plates with hydroethanolic extract of Musa $\times$ paradisiaca (banana) at concentrations of $10 \%, 30 \%$, and $50 \%$, the positive control (nystatin) and the negative control ( $96 \%$ ethanol)

to the hydroethanolic extract of $M . \times$ paradisiaca (banana) at concentrations of $10 \%, 30 \%$, and $50 \%$, the positive control (nystatin), and the negative control ( $96 \%$ ethanol) (Figs 2B and C).

\section{Antimicrobial Test}

Subsequently, using a sterile punch of $6 \mathrm{~mm}$ in diameter, five wells ( $6 \mathrm{~mm}$ deep) were made in each plate. To each well, $50 \mu \mathrm{L}$ of the hydroethanolic extract at each concentration and controls were added. The plates were left for an hour to allow sample diffusion into the agar, followed by incubation at $37^{\circ} \mathrm{C}$ for 24 hours.

\section{Reading the Results}

After 24 hours of incubation, each plate was examined, and the diameter $(\mathrm{mm})$ of the growth inhibition halos around each well was measured using a digital vernier caliper. Ten replicates of each assay were performed.

\section{Data Analysis}

Experimental data were entered into the database in IBM SPSS Statistics version 23 and later worked with the ANOVA statistical test and Duncan test on the assumption of normal distribution.

\section{Results}

\section{Average Sizes of Inhibition Halos for the Hydroethanolic Extract (E.E.) of the Musa $\times$ paradisiaca Peel against $C$. albicans strain ATCC 10231}

The $10 \%$ hydroethanolic extract of the $M . \times$ paradisiaca peel produced an inhibition halo of $8.2 \mathrm{~mm}$, with a standard deviation of $1.03 \mathrm{~mm}$; at $30 \%$, the mean diameter and the standard deviation were 10.5 and $1.74 \mathrm{~mm}$, respectively; at $50 \%$, the mean diameter was $12.5 \mathrm{~mm}$ and the standard deviation was $1.86 \mathrm{~mm}$, while the average diameter in the nystatin group was $8.9 \mathrm{~mm}$ (Table 1).

\section{Analysis of Variance of the Diameters of Inhibition Halos $(\mathrm{mm})$}

When the data were subjected to the $F$ test of ANOVA, comparing the means of each study group, a value of $F=18.229$ was obtained, with a significant difference $(p<0.001)$, i.e., the different concentrations produced different mean effects (Table 2 ).

\section{Comparison of the Diameters of Inhibition Halos (mm) According to the Treatment Group}

In this multiple comparison test, the Duncan test was applied, and it was observed that the hydroethanolic extract of $M$. $\times$ paradisiaca
Table 1: Average sizes of inhibition halos for the hydroethanolic extract (E.E.) of the Musa $\times$ paradisiaca peel against Candida albicans strain ATCC 10231

\begin{tabular}{llcl}
\hline Treatment groups & $n$ & Average $(\mathrm{mm})$ & Standard dev. \\
\hline $\begin{array}{l}\text { E.E. Musa } \times \text { paradisiaca } \\
10 \%\end{array}$ & 10 & 8.2 & 1.03 \\
$\begin{array}{l}\text { E.E. Musa } \times \text { paradisiaca } \\
\text { 30\% }\end{array}$ & 10 & 10.5 & 1.74 \\
$\begin{array}{l}\text { E.E. Musa } \times \text { paradisiaca } \\
\text { 50\% }\end{array}$ & 10 & 12.5 & 1.86 \\
Nystatin (control +) & 10 & 8.9 & 0.43 \\
\hline
\end{tabular}

at $10 \%$ and nystatin showed no significant difference $(p>0.05)$. However, there were differences at the other concentrations of the extract (30\% and 50\%), which indicated different effects of the concentrations in terms of the strain susceptibility, which is expressed as a diameter of the inhibition halo (Table 3 ).

\section{Discussion}

In the present study, positive results were obtained for antifungal activity of three different extract concentrations (10\%, 30\%, and $50 \%$ ) and a positive control (nystatin) against a strain of C. albicans using the agar diffusion method. The results confirmed the findings of other authors, such as Fugaban ${ }^{9}$ and Karadi, ${ }^{10}$ who demonstrated the antifungal activity of $M . \times$ paradisiaca against $C$. albicans.

According to Nagalingam, ${ }^{11}$ this medicinal plant could be used in the treatment of diseases caused by organisms such as C. albicans.

The antifungal activity of the $10 \%$ hydroethanolic extract against the strain of $C$. albicans was shown to result in an inhibition halo of $8.2 \mathrm{~mm}$, which was comparable to that of nystatin, which produced an inhibition halo of $8.9 \mathrm{~mm}$, showing no significant difference.

Regarding the antifungal activity of the $30 \%$ hydroethanolic extract against the strain of C. albicans, a $10.5-\mathrm{mm}$ inhibition halo was observed, demonstrating a greater antifungal activity than that of nystatin.

The study by Karadi ${ }^{10}$ showed that $M . \times$ paradisiaca exerted a potent inhibitory effect against fungal strains, with the antifungal activity as strong as fluconazole. In this study, it was demonstrated that $M . \times$ paradisiaca showed a greater inhibitory activity than that of nystatin. 
Table 2: Analysis of variance of the diameters of inhibition halos ( $\mathrm{mm}$ )

\begin{tabular}{lrrrrl}
\hline SV & \multicolumn{1}{l}{ SS } & $d f$ & MS & $F$ & $p$ \\
\hline Treatment & 105.682 & 3 & 35.227 & 18.229 & 0.0000 \\
Error & 69.569 & 36 & 1.932 & & \\
Total & 175.251 & 39 & & & \\
\hline
\end{tabular}

SV, source of variation; SS, sum of squares; DF, degree of freedom; MS, mean square; $F$, comparison of several variables; $p$, probability

Table 3: Comparison of the diameters of inhibition halos ( $\mathrm{mm}$ ) according to the treatment group

\begin{tabular}{llllc}
\hline & & \multicolumn{3}{c}{ Subset for $\alpha=0.05$} \\
\cline { 3 - 5 } Treatment groups & $n$ & 1 & 2 & 3 \\
\hline E.E. Musa $\times$ paradisiaca 10\% & 10 & 8.2 & & \\
Nystatin (control +) & 10 & 8.9 & & \\
E.E. Musa $\times$ paradisiaca 30\% & 10 & & 10.5 & \\
E.E. Musa $\times$ paradisiaca 50\% & 10 & & & 12.5 \\
\hline
\end{tabular}

Finally, the antifungal activity of the $50 \%$ hydroethanolic extract against the $C$. albicans strain resulted in an inhibition halo of 12.5 $\mathrm{mm}$, which was the highest activity among the three concentrations of the extract, along with the positive control, in agreement with the data of other studies, such as that by Fugaban, ${ }^{9}$ in which the $50 \%$ concentration of an $M . \times$ paradisiaca extract exhibited the highest antifungal activity against $C$. albicans.

Kapadia ${ }^{12}$ demonstrated that the extract used in their study produced a larger inhibition zone (24 $\mathrm{mm}$ in diameter) against $C$. albicans than against all other bacteria and fungi studied.

In this study, among all concentrations, the $50 \%$ concentration of the $M . \times$ paradisiaca extract exhibited the highest antifungal activity against $C$. albicans. It was observed that compared with the other concentrations, the $50 \%$ concentration of the hydroethanolic extract of $M . \times$ paradisiaca produced the largest average inhibition halo, with a diameter of $12.5 \mathrm{~mm}$, which exceeded that of 6.625 nystatin (diameter $=8.9 \mathrm{~mm}$ ).

Similar results were reported in the study by Fugaban, ${ }^{9}$ which compared the effects of an $M . \times$ paradisiaca extract at concentrations of $100 \%, 50 \%$, and $30 \%$ against C. albicans. The results indicated that the extract at a concentration of $50 \%$ was more effective against $C$. albicans. Thus, the results were similar to ours and provided baseline information on the antifungal properties of $M . \times$ paradisiaca against $C$. albicans.

Likewise, our data were compared with those obtained in the study by Egbuonu ${ }^{2}$ who concluded that bananas possessed antifungal properties against $C$. albicans.

The antimicrobial activity of hydroethanolic extracts of $M . \times$ paradisiaca depends on several factors, ${ }^{11,13-16}$ including the harvest season, geographic location, extraction method, fruit maturity index, variety, and chemical structure of the components of the oil and its concentration. ${ }^{17,18}$ The storage time and conditions also influence the antimicrobial activity because hydroethanolic extracts are very sensitive to light and high temperatures. ${ }^{19-21}$ Thus, these factors can affect the inhibitory power of the extract. In this study, these factors were controlled to preserve the composition of the hydroethanolic extract of $M$. $\times$ paradisiaca and its antifungal power. $^{10,22,23}$

Currently around 3,000 natural substances were studied, of which only $10 \%$ have a positive impact on the pharmaceutical industry. ${ }^{24-27}$ The components of these products are secondary metabolites of plants that can be physically separated from the membranous tissue. ${ }^{28,29}$ Thus, for example, traditionally, essential oils have been used as bactericides, fungicides, antiparasitics, analgesics, and spasmolytics. ${ }^{30,31}$ However, the lipophilic nature of essential oils makes its administration difficult to be used as antimicrobial agents. ${ }^{14,32,33}$ The literature has shown that monoterpenes present in many of these substances such as that of $M . \times$ paradisiaca have shown high fungicidal activity against $C$. albicans, similar to the fungistatic of nystatin. ${ }^{9,12,22,34-36}$ However, in spite of the objectives set out in this study, it is necessary to know more deeply the mechanisms of action of this natural product, analyzing its composition and synergistic effect. ${ }^{37-40}$ The literature on $M . \times$ paradisiaca as such is less, which can be considered a limitation for this study in the statistical as well as theoretical part. However, the high frequency of edentulous patients and patients carrying prostheses in conjunction with the results found invite new studies to be carried out in this same line, seeking to find the appropriate antifungal that in addition to controlling fungal infection prevents any alteration to the mouth structures where it makes contact.

The result obtained in this study clearly demonstrates that banana fruit peel has a broad spectrum of biological activities and could be used as a good source of antifungal agent. However, to continue with the search for new antibacterial agents, it is necessary to test the great variety of this species that are potential source of bioactive agents and also to evaluate its pharmaceutical properties, such as its pharmacodynamics, pharmacokinetics, and toxicity, among others

\section{ConClusion}

The hydroethanolic extract of the $M . \times$ paradisiaca peel showed a greater antifungal effect against a strain of $C$. albicans. With the results of the executed in vitro study, it converts $M . \times$ paradisiaca into a therapeutic alternative for candidiasis, reducing the frequency of side effects caused by chlorhexidine and other chemical substances.

\section{Author Contributions}

All authors conceived, designed, written, revised and improved the study.

\section{Human and Animal Rights}

No animals/humans were used for studies that are base of this research.

\section{Availability of Data and Materials}

The data sets used and/or analyzed during the current study are available from the corresponding author on request. 


\section{References}

1. Bertolini M, Dongari-Bagtzoglou A. The relationship of Candida albicans with the oral bacterial microbiome in health and disease. Adv Exp Med Biol 2019;11(1):69-78. DOI: 10.1007/978-3-03028524-1_6.

2. Egbuonu A, Ogele O, Amaraihu K. Comparative evaluation of the proximate composition and antibacterial activity of ground Musa paradisiaca (plantain) peels and leaves. British Biotech J 2016;15(2): 1-9. DOI: 10.9734/BBJ/2016/27151.

3. Blanco-Olano J, Millones-Gómez PA. Cicatrizing effect of Aloe vera gel with erythroxy coca in animal model. Med Nat 2020;14(1):65-74.

4. Millones-Gómez P, Aguirre A. Efficacy of azithromycin associated with RAR in chronic periodontitis: clinical trial, randomized, controlled, triple blind parallel groups. Rev Esp Cirug Oral y Maxilofac 2018;40(3):129-134.

5. Rodriguez-Perez J, Joana L, Pablo A, et al. Effect of Annona muricata L. leaves on Streptococcus mutans ATCC 25175 Strains. 2019;13(10): ZC13-ZC16.

6. Becerra TB, Calla-poma RD, Requena-mendizabal MF, et al. Antibacterial effect of peruvian propolis collected during different seasons on the growth of Streptococcus mutans. The Open Dent J 2019;13(1):327-331. DOI: 10.2174/1874210601913010327.

7. Alvarado Saavedra SL, Herrera-Plasencia P, Enoki-Miñano E, et al. In vitro antibacterial activity of an ethanolic extract of prosopis pallida against enterococcus faecalis ATCC 29212. Rev Cubana Med Trop 2018;70(2):1-12.

8. Mayorga J. Inhibitory effect of the extract of the Musa paradisiaca in different concentrations and different times against the Porphyromona gingivalis, in vitro study [Thesis]. Ecuador: Central University of Ecuador. Faculty of Dentistry 2017.

9. Fugaban C. Comparative study on the antifungal property of banana and papaya peel extract on Candida albicans when added to glucose yeast peptone agar. Sch Acad J Biosci 2016;4(2):154-157.

10. Karadi RV, Shah A, Parekh P, et al. Antimicrobial activities of Musa paradisiaca and Cocos nucifera. Int J Res Pharmaceut Biomed Sci 2011;2(1):264-267.

11. Nagalingam M, Arumugam G, Panneerselvam A. Antimicrobial activity of some Indian folklore medicinal plants against drug resistant bacteria and fungi isolated from clinical samples. Asian J Plant Sci Res 2015;5(6):49-56.

12. Kapadia SP, Pudakalkatti PS, Shivanaikar S. Detection of antimicrobial activity of banana peel (Musa paradisiaca L.) on Porphyromonas gingivalis and Aggregatibacter actinomycetemcomitans: An in vitro study. Contemp Clin Dent 2015;6(4):496-499. DOI: 10.4103/0976237X.169864.

13. Qi D, Zou L, Zhou D, et al. Taxonomy and broad-spectrum antifungal activity of streptomyces sp. SCA3-4 isolated from rhizosphere soil of Opuntia stricta. Front Microbiol 2019;10:1390. DOI: 10.3389/ fmicb.2019.01390.

14. Jiao W, Li X, Zhao H, et al. Antifungal activity of an abundant thaumatin-like protein from banana against Penicillium expansum, and its possible mechanisms of action. Molecules 2018;23(6):24-29. DOI: $10.3390 /$ molecules 23061442 .

15. Hsu LH, Wang HF, Sun PL, et al. The antibiotic polymyxin B exhibits novel antifungal activity against Fusarium species. Int J Antimicrob Agents 2017;49(6):740-748. DOI: 10.1016/j.ijantimicag.2017. 01.029.

16. Dikhoba PM, Mongalo NI, Elgorashi EE, et al. Antifungal and antimycotoxigenic activity of selected South African medicinal plants species. Heliyon 2019;5(10):e02668. DOI: 10.1016/j.heliyon.2019. e02668.

17. Sampaio TP, Cartaxo-Furtado NA, de Medeiros AC, et al. Antimicrobial potential of plant extracts and chemical fractions of Sideroxylon obtusifolium (Roem. \& Schult.) T.D. Penn on oral microorganisms. J Contemp Dent Pract 2017;18(5):392-398. DOI: 10.5005/ jp-journals-10024-2053.
18. Van Vuuren SF, Viljoen AM. In vitro evidence of phyto-synergy for plant part combinations of Croton gratissimus (Euphorbiaceae) used in African traditional healing. J Ethnopharmacol 2008;119(3):700-704. DOI: 10.1016/j.jep.2008.06.031.

19. Chipinga JV, Kamanula JF, Moyo PBB. Efficacy of Pterocarpus angolensis crude extracts against Candida krusei, Staphylococcus aureus, Streptococcus agalactiae and Escherichia coli. Malawi Med J 30(4):219-224. DOI: 10.4314/mmj.v30i4.2.

20. Teodoro GR, Gontijo AVL, Salvador MJ, et al. Effects of acetone fraction from Buchenavia tomentosa aqueous extract and gallic acid on Candida albicans biofilms and virulence factors. Front Microbiol 2018;9(1):647-662. DOI: 10.3389/fmicb.2018.00647.

21. Ferreira GL, Pérez AL, Rocha íM, et al. Does scientific evidence for the use of natural products in the treatment of oral candidiasis exist? A systematic review. Evid Based Complement Alternat Med 2015;14(7):80-94. DOI: 10.1155/2015/147804.

22. Karuppiah P, Mustaffa M. Antibacterial and antioxidant activities of Musa sp. leaf extracts against multidrug resistant clinical pathogens causing nosocomial infection. Asian Pac J Trop Biomed 2013;3(9):737742. DOI: 10.1016/S2221-1691(13)60148-3.

23. Lavaee $F$, Motaghi D, Jassbi AR, et al. Antifungal effect of the bark and root extracts of Punica granatum on oral Candida isolates. Curr Med Mycol 2018;4(4):20-24. DOI: 10.18502/cmm.4.4.382.

24. Behbehani JM, Irshad M, Shreaz S, et al. Synergistic effects of tea polyphenol epigallocatechin 3-O-gallate and azole drugs against oral Candida isolates. J Mycol Med 2019;29(2):158-167. DOI: 10.1016/ j.mycmed.2019.01.011.

25. Davaadorj M, Ser-Od T, Al-Wahabi A, et al. Effect of Mongolian herbal tea on growth of Candida albicans. Bull Tokyo Dent Coll 2019;60(1):61-66. DOI: 10.2209/tdcpublication.2018-0021.

26. Raghavan R, Devi MPS, Varghese M, et al. Effectiveness of Mentha piperita leaf extracts against oral pathogens: an in vitro study. J Contemp Dent Pract 2018;19(9):1042-1046. DOI: 10.5005/ jp-journals-10024-2378.

27. Nittayananta W, Limsuwan S, Srichana T, et al. Oral spray containing plant-derived compounds is effective against common oral pathogens. Arch Oral Biol 2018;90:80-85. DOI: 10.1016/ j.archoralbio.2018.03.002.

28. Chevalier M, Ranque S, Prêcheur I. Oral fungal-bacterial biofilm models in vitro: a review. Med Mycol 2018;56(6):653-667. DOI: 10.1093/ $\mathrm{mmy} / \mathrm{myx} 111$.

29. Naito Y, Yumoto H, Kumar HSK, et al. Antifungal and mechanical properties of tissue conditioner containing plant-derived component: an in vitro study. J Prosthodont 2018;27(7):665-669. DOI: 10.1111/ jopr.12546.

30. Hoare A, Marsh PD, Diaz PI. Ecological therapeutic opportunities for oral diseases. Microbiol Spectr 2017;5(4):10-11. DOI: 10.1128/ microbiolspec.BAD-0006-2016.

31. Sushma R, Sathe TT, Farias A, et al. "Nature cures:" An alternative herbal formulation as a denture cleanser. Ann Afr Med 2017;16(1):6-12. DOI: 10.4103/aam.aam_43_16.

32. Tejada G, Barrera MG, Piccirilli GN, et al. Development and evaluation of buccal films based on chitosan for the potential treatment of oral candidiasis. AAPS PharmSciTech 2017;18(4):936-946. DOI: 10.1208/ s12249-017-0720-6.

33. Labib GS, Aldawsari H. Innovation of natural essential oil-loaded orabase for local treatment of oral candidiasis. Drug Des Devel Ther 2015;9(1):3349-3359. DOI: 10.2147/DDDT.S85356.

34. Sirajudin Z, Ahmed Q, Chowdhury A. Antimicrobial activity of banana (Musa paradisiaca L.) peels against food borne pathogenic microbes. J Pure Appl Microbiol 2014;1(8).

35. Okorondu S, Akujobi C, Nwachukwu I. Antifungal properties of Musa paradisiaca (Plantain) peel and stalk extracts. Int. J Biol Chem Sci 2012;6(4):1527-1534.

36. Rossoni RD, Dos Santos Velloso M, Figueiredo LMA, et al. Clinical strains of Lactobacillus reduce the filamentation of Candida albicans and protect Galleria mellonella against experimental candidiasis. 
Folia Microbiol (Praha) 2018;63(3):307-314. DOI: 10.1007/s12223-0170569-9.

37. Hayama K, Takahashi M, Suzuki M, et al. Anti-Candida activity of aroma candy and its protective activity against murine oral candidiasis. Med Mycol J 2015;56(1):J23-J29. DOI: 10.3314/mmj.56.J23.

38. Girardot $M$, Guerineau $A$, Boudesocque $L$, et al. Promising results of cranberry in the prevention of oral Candida biofilms. Pathog Dis 2014;70(3):432-439. DOI: 10.1111/2049-632X.12168.
39. Ninomiya K, Maruyama N, Inoue S, et al. The essential oil of Melaleuca alternifolia (tea tree oil) and its main component, terpinen-4-ol protect mice from experimental oral candidiasis. Biol Pharm Bull 2012;35(6):861-865. DOI: 10.1248/bpb.35.861.

40. Silva DR, Rosalen PL, Freires IA, et al. Anadenanthera Colubrina vell Brenan:anti-Candida and antibiofilm activities, toxicity and therapeutical action. Braz Oral Res 2019;33:e023. DOI: 10.1590/18073107bor-2019.vol33.0023. 